\title{
Role of orography in the spatial distribution of precipitation over the Spanish Mediterranean zone
}

\author{
M. G. Sotillo ${ }^{1, *}$, C. Ramis ${ }^{1}$, R. Romero ${ }^{1}$, S. Alonso ${ }^{1,2}$, V. Homar ${ }^{1}$ \\ ${ }^{1}$ Meteorology Group, Departament de Física, Universitat de les Illes Balears, 07071 Palma de Mallorca, Spain \\ ${ }^{2}$ Institute Mediterrani d'Estudis Avançats (IMEDEA), Universitat de les Illes Balears - Consejo Superior de Investigaciones \\ Científicas (UIB-CSIC), 07071 Palma de Mallorca, Spain
}

\begin{abstract}
The effects of orography on the precipitation field in the Spanish Mediterranean zone are studied through numerical simulations from a climatological point of view. The main atmospheric patterns that produce significant precipitation in the considered area, derived in a previous study, have been used as input data. The numerical simulations have been performed using the HIRLAM model. We isolate, by means of a factor-separation technique, the separate effects of the Iberian and non-Iberian orographies, as well as the synergy between the 2 orographies. The diversity of simulated-precipitation spatial distributions is clearly linked to the wide variety of flows over the Iberian Peninsula. However, a clear distinction between Atlantic and western Mediterranean disturbances is obtained. When Atlantic westerlies occur over the Iberian Peninsula, rainfall in the Spanish Mediterranean zone is enhanced by orography, mainly by that of Iberia. Otherwise, when the Iberian Peninsula is affected by Mediterranean disturbances, local orographic enhancements along with the redistribution of precipitation due to non-Iberian orography and synergistic effects are observed. The North African Atlas range, due to its primary influence, emerges as one of the factors governing the spatial distribution of rainfall across the Spanish Mediterranean zone.
\end{abstract}

KEY WORDS: Western Mediterranean · Precipitation · Numerical simulation · Orographic effects · Factor separation

Resale or republication not permitted without written consent of the publisher

\section{INTRODUCTION}

The western Mediterranean basin is surrounded by important mountain ranges, which reach its coastline. Such ranges isolate the basin from other regions other than through valleys and narrow straits. The main ranges which confine the western Mediterranean basin are the Atlas in the south, the Alps, the Pyrenees and the French Central Massif in the north, the Sistema Ibérico and Penibético in the west, and, in addition, the abrupt mountains of Corsica and Sardinia in the east (Fig. 1a).

This overall orography plays a major role in the configuration of the regional climate. In fact, orography, acting as a mechanism of cyclogenesis at synoptic and meso-scales, becomes one of the factors ruling the atmospheric circulation. It works by generating sec- ondary cyclones to the lee of the Atlas, Alps and Pyrenees as response to certain tropospheric flows (Reiter 1975). At local scales, the pronounced relief of the area strengthens precipitation-generating mechanisms, assisting the development of clouds at fixed locations or enhancing precipitation from pre-existing cloud systems. In addition to this, the western Mediterranean Sea has high surface temperatures for much of the year, and it is therefore an important water vapour source. Under appropriate meteorological conditions, when atmospheric flux impinges over the coastal ranges, the evaporation leads to an intensification of the above mechanisms, as well as facilitating organized convection over coastal areas. All these factors make orography a leading mechanism in the spatial distribution of rainfall. Specifically, rainfall is strongly affected by orography in the Spanish Mediterranean 
a

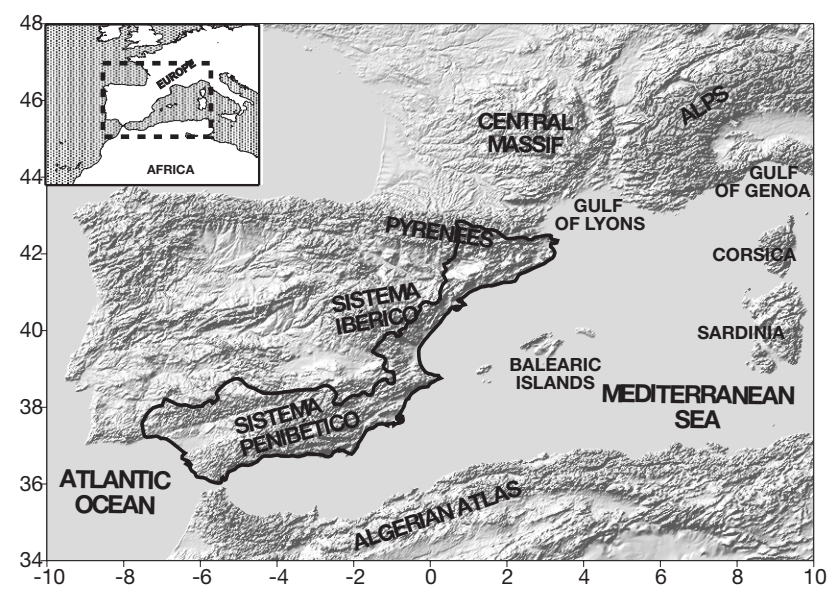

zone (Fig. 1). Romero et al. (1999a), using a database of $30 \mathrm{yr}$ and 410 rain-gauges, produced a classification of the spatial distribution of significant daily rainfalls for that zone. The classification was accomplished by principal-component and cluster analyses, from which 11 pattern groups were obtained. After a visual inspection of both those pattern groups and the orography of the region, the authors concluded that exposure to or shelter from rain-bearing systems afforded by the complex orography is enough of a determinant to produce a clear regionalization of rainfall. Correspondence between pattern groups and local features of orography is high and reflects qualitatively the strong relationship between orography and rainfall distribution in the Spanish Mediterranean zone. The same can be deduced from annual mean precipitation over the Iberian Peninsula (Font 1983); major rainfalls tend to occur over the main mountain ranges.

b

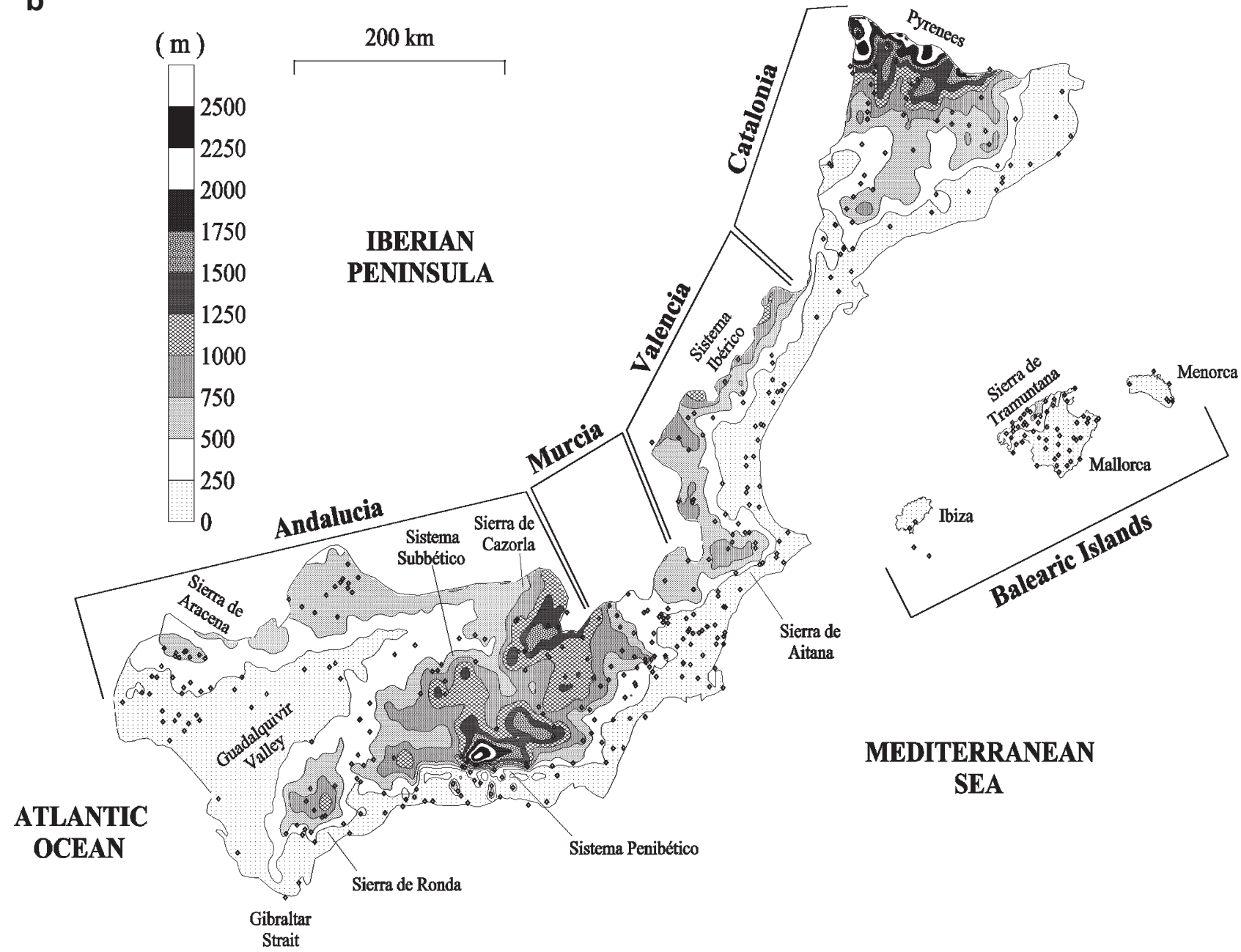

Fig. 1. (a) The Western Mediterranean basin. Sites and mountain ranges referred to in the text are indicated. Bounded region represents the Spanish Mediterranean zone; (b) more detailed orography and names of the ranges and regions. Location of the 410 rain-gauge stations used to validate the results is also indicated 
Romero et al. (1999b) showed that precipitation in the Spanish Mediterranean zone occurs under certain synoptic situations. In fact, using European Centre for Medium range Weather Forcast (ECMWF) data from 1984 to 1993 they found, through principal-component and cluster analyses, 19 atmospheric patterns which produce significant precipitation (their Fig. 5). They also showed that interaction between orography and synoptic flux could explain, at least partially, the spatial distribution of precipitation. Thus there is clear evidence of the relation between orography, airflow and precipitation in the Spanish Mediterranean zone.

The main objective of this study is to quantify the orographic effect on the precipitation field in the Spanish Mediterranean zone. Although this effect has been studied for several cases of heavy-precipitation events (Romero et al. 1997, Ramis et al. 1998, Homar et al. 1999), it has not been faced from a climatological point of view. To this aim a set of numerical simulations using the HIRLAM model were performed for the different synoptic situations which have been shown to produce significant rainfall in the region. These simulations were carried out using as initial conditions each of the 19 aforementioned synoptic atmospheric precipitation-producing patterns.

A second objective is to isolate the influence of the Iberian orography on the precipitation field as distinct from the external orography, paying special attention to the effect of the Atlas range and the Alps because of their already-demonstrated dominant role in Mediterranean weather (e.g. Buzzi \& Tibaldi 1978, Homar et al. 1999). This is accomplished using the factor-separation technique of Stein \& Alpert (1993). This method allows us to quantify not only the separate effect of Iberian and non-Iberian orography but also the effect of interaction between them.

The present paper is organized as follows: Section 2 provides a description of the method used to obtain a set of initial and boundary conditions for each atmospheric pattern. The numerical model is briefly described in Section 3. Section 4 presents an overview of the factor-separation technique, as well as a detailed description of the different simulations performed. Results of the experiments are described in detail in Section 5. Finally, in Section 6, main conclusions are given.

\section{REPRESENTATIVE METEOROLOGICAL SITUATIONS}

In order to carry out the aforementioned numerical simulations, we first select a real meteorological situation representative of each atmospheric pattern. Several methods could be applied to carry out this selec-
Table 1. Correlation coefficients between the precipitation fields of the selected representative day and the composite for each of the 19 atmospheric pattern groups (AP)

\begin{tabular}{|rc|}
\hline AP & Correlation \\
\hline 1 & 0.83 \\
2 & 0.91 \\
3 & 0.91 \\
4 & 0.88 \\
5 & 0.81 \\
6 & 0.56 \\
7 & 0.73 \\
8 & 0.70 \\
9 & 0.76 \\
10 & 0.59 \\
11 & 0.66 \\
12 & 0.85 \\
13 & 0.81 \\
14 & 0.72 \\
15 & 0.70 \\
16 & 0.56 \\
17 & 0.91 \\
18 & 0.72 \\
19 & 0.86 \\
\hline
\end{tabular}

tion. For this study, we represent each atmospheric pattern by the day of the pattern-defining cluster showing the precipitation field most similar to the composite precipitation calculated from all members in the cluster. This criterion is followed since the main aim of this work is to obtain information about the characteristic precipitation field associated with each of the 19 atmospheric pattern groups. As a measure of similarity between the individual and composite precipitation fields, correlation coefficients are used. Then the day exhibiting the maximum correlation value is selected. To perform this correlation analysis, rainfall data from the 410 stations shown in Fig. 1b are used. As can be seen in Table 1, 15 of the 19 selected days show correlation values with the precipitation composite higher than 0.7 .

Fig. 2 shows observed individual and composite precipitation fields for 5 of these situations, representative of the main rain-bearing flow regimes.

\section{NUMERICAL MODEL}

The simulations were performed with the hydrostatic numerical model HIRLAM, which is the result of a co-operative project of the national weather services in Denmark, Finland, Iceland, Ireland, The Netherlands, Norway, Spain and Sweden for developing a system suitable for short-range numerical weather prediction. Currently, the HIRLAM model is used by some European meteorological services as an operational forecasting system. 

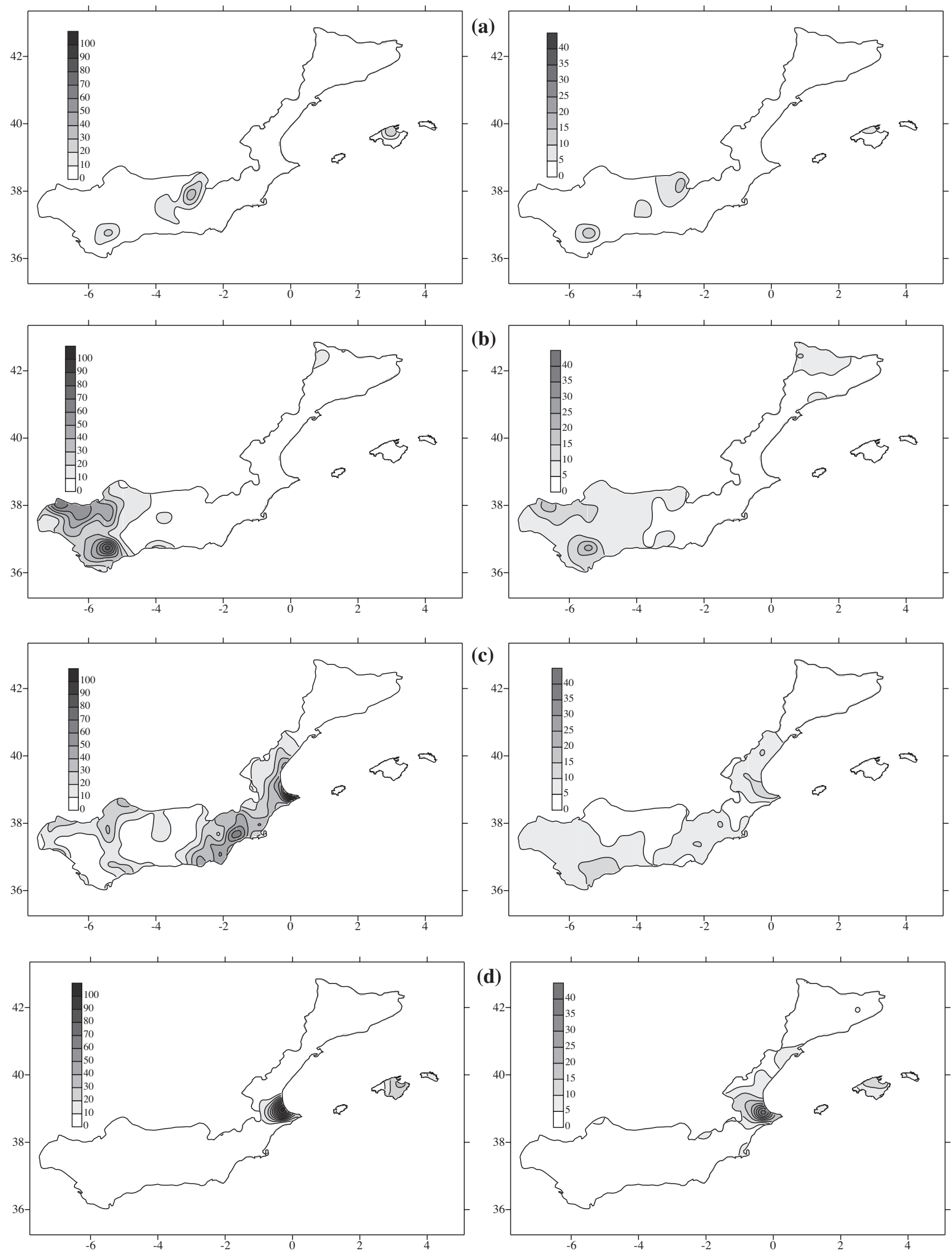

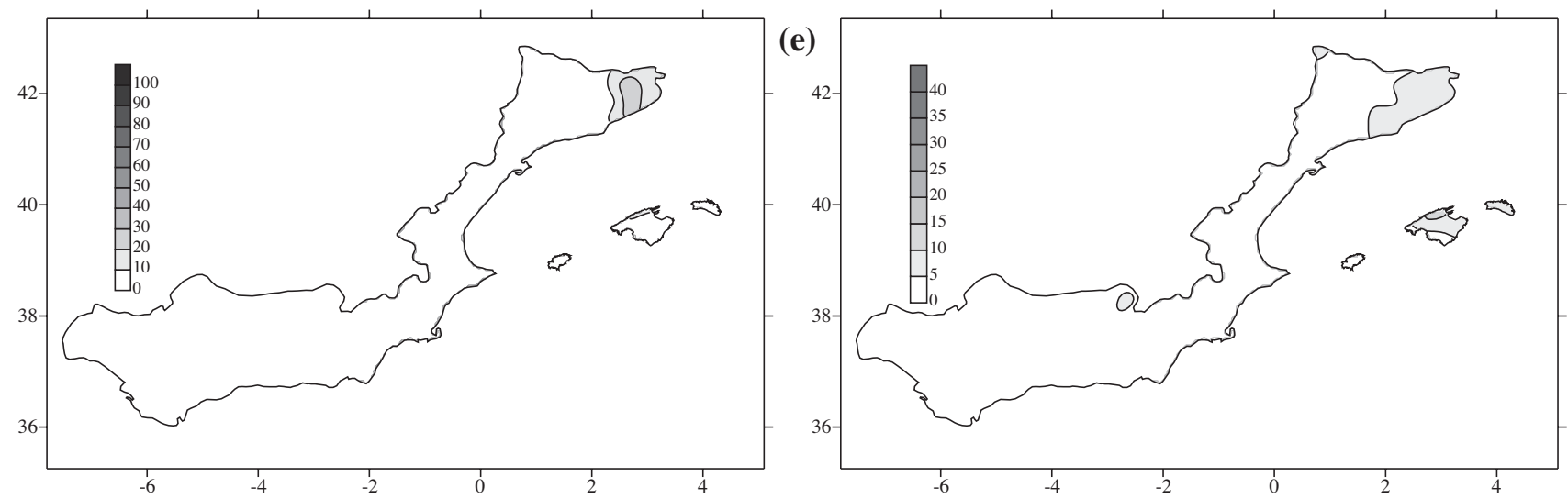

Fig. 2. (Facing page and above). Left panels: Observed precipitation field associated with the selected representative day. Right panels: Precipitation composite of its atmospheric pattern group. (a) Cold front passage; (b) Atlantic flows; (c) southwestern disturbances aloft; (d) southeastern disturbances aloft; (e) Northerly flows. Note the different scale between day and composite precipitation maps

The numerical model is horizontally formulated for an Arakawa C-grid, whereas the vertical formulation corresponds to the hybrid system used at ECMWF (31 $p-\sigma$ vertical levels). Prognostic equations for the horizontal wind, temperature, surface pressure and moisture, as well as an additional equation for cloud liquid water, are solved. An Eulerian semi-implicit time scheme (Källén 1996) was used. A fourth-order explicit linear horizontal diffusion scheme is implemented on every prognostic variable, except for liquid cloud water.

Physical processes such as radiation (short and long wave), vertical diffusion, stratiform condensation, convection and surface processes, all of them contributing on the sub-grid scale, were considered. Parameterization of short- and long-wave radiative energy transfer was accomplished by following Savijärvi (1990). Vertical diffusion of momentum, sensible heat and moisture caused by turbulence fluxes was resolved by following Louis (1979). In order to avoid underestimation of the magnitude of turbulent fluxes and consequently the creation of a shallow and too moist planetary boundary layer (PBL), a parameterization of shallow convection (Källén 1996) in the vertical diffusion scheme was considered.

The cloud scheme of Sundqvist et al. (1989) was applied; it combines convective and stratiform condensation along with parametrization of microphysical processes, such as release of precipitation, evaporation and melting of hydrometeors.

For the purpose of the model's initialization, the Temperton (1988) version of the original non-linear, normal-mode initialization scheme of Machenhauer (1977) was used. It eliminates spurious oscillations caused by the fast modes (gravity modes) by iteratively setting their tendencies to zero.

\section{DESCRIPTION OF THE EXPERIMENTS}

Simulations were performed over the region 31.65$48.75^{\circ} \mathrm{N}, 18.00^{\circ} \mathrm{W}-12.30^{\circ} \mathrm{E}$, centred on eastern Spain (Fig. 3). That domain is wide enough to incorporate the complete Iberian Peninsula, the French Central Massif, and most of the Alps. The suspected influence of the Atlas range under mid-level southerly flows on cyclogenesis over the southern part of the Western Mediterranean (Reiter 1975) was a ruling factor in the selection of the domain. Consequently, the region used includes most of the Atlas range.

Numerical experiments were performed with a horizontal resolution of $0.3^{\circ} \times 0.3^{\circ}$ (roughly $30 \times 30 \mathrm{~km}^{2}$ ). With this horizontal resolution, a grid of $102 \times 58$ points defines the model domain. Vertically, 31 hybrid levels were considered. The time step used for the model integration was $90 \mathrm{~s}$. Non-initialized ECMWF analyses, with $0.75^{\circ}$ resolution and available at 00:00, 06:00,

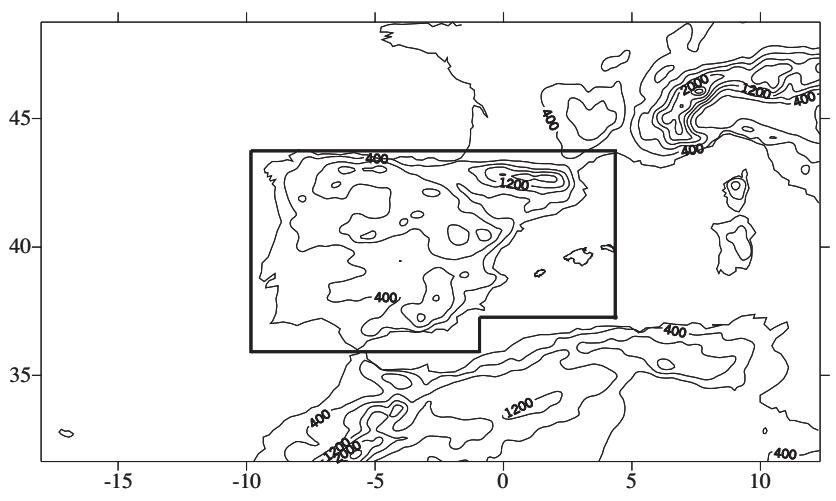

Fig. 3. Domain and orography $(\mathrm{m})$ used for the model simulations. Orographies into the marked area and outside are referred to as local and non-local, respectively, in the study 
12:00 and 18:00 h UTC, were used to set initial and boundary conditions. In order to minimize the propagating errors from the lateral boundaries into the forecast area, a cosine-shaped relaxation function over an 8-point boundary region was used (Davies 1976).

Soil processes were considered using a 3-layer model. The evolution of temperature and soil water was calculated using a force-restore method initialized with climatic data. For sea-surface temperature, a climatic monthly mean value was used and kept constant during the experiments.

Available rainfall observations used to verify the simulated precipitation corresponded to a $24 \mathrm{~h}$ period (from 07:00 h UTC to 07:00 h UTC the next day). On account of this, we extended our simulations to a $30 \mathrm{~h}$ period to include a spin-up initial period. Thus, simulations started at 00:00 h UTC and ended at 06:00 h UTC the next day, but the forecasted accumulated precipitation is only considered from $06: 00 \mathrm{~h} \mathrm{UTC}$ to $06: 00 \mathrm{~h}$ UTC the next day.

The study of the total effect of the orography, as well as the individual role of the Iberian and nonIberian ranges and their synergism, requires multiple simulations with different model orography configurations. First, a complete simulation (CS) for each of the 19 selected days, which will reveal the model's capability to simulate the precipitation field of the corresponding atmospheric pattern. Second, nonorographic simulations (NOS), identical to the previous ones but with flat terrain. Differences in the simulated precipitation between CS and NOS for each atmospheric pattern will give us basically the role played by orography in influencing the precipitation field, although the NOS will still contain small orographic influences imposed by the real initial and boundary meteorological data used.

Once the total orographic effect on rainfall distributions is obtained, it seems desirable to isolate the effect caused by the Iberian Peninsula's orography, considering it as a local effect, as distinct from the remote effect due to far orographic systems. The latter is referred to as non-local orography in the text, and it includes every mountain range sited outside the Iberian Peninsula and Balearic Islands (Fig. 3).

Such individual contributions can be obtained by following the factor-separation technique of Stein \& Alpert (1993). In essence, the technique consists of combining a set of adequately configured numerical simulations in order to isolate the effects of any considered factors. Specifically, it is necessary to perform $2^{n}$ simulations to isolate the effect of $n$ factors. Therefore, since 2 factors are considered here (local and non-local orographies), 2 more simulations are necessary in addition to the above-described CS and NOS: one simulation including only the Iberian Peninsula orography (IPOS), and a complementary one with all the orogra- phy except that corresponding to the Iberian Peninsula (NIPOS). With these 2 extra simulations, it becomes feasible to separate not only the individual effects, but also the synergistic interaction between local and nonlocal orographies. The separation method is formulated after recognising that the different simulations will comprise a different combination of effects:

$$
\begin{aligned}
\mathrm{CS} & =E_{\mathrm{L}}+E_{\mathrm{NL}}+E_{\mathrm{Int}}+E_{0} \\
\mathrm{NOS} & =E_{0} \\
\mathrm{IPOS} & =E_{\mathrm{L}}+E_{0} \\
\text { NIPOS } & =E_{\mathrm{NL}}+E_{0}
\end{aligned}
$$

where $E_{\mathrm{L}}$ is the effect of the local orography, $E_{\mathrm{NL}}$ is the effect of the non-local orography, $E_{\text {Int }}$ is the co-operative effect of both factors, and $E_{0}$ contains any other contribution not attributable to the action of these orographies. Thus, the 4 simulations can be algebraically combined to isolate the previous individual orographic effects:

$$
\begin{aligned}
E_{\mathrm{L}} & =\text { IPOS }- \text { NOS } \\
E_{\mathrm{NL}} & =\text { NIPOS }- \text { NOS } \\
E_{\text {Int }} & =\text { CS }-(\text { NIPOS }+ \text { IPOS })+\text { NOS }
\end{aligned}
$$

Note that the total effect of the orography $\left(E_{\mathrm{T}}\right)$ is defined by:

$$
E_{\mathrm{T}}=E_{\mathrm{L}}+E_{\mathrm{NL}}+E_{\mathrm{Int}}=\mathrm{CS}-\mathrm{NOS}
$$

To conclude, we point out that the contribution of non-local orography to the precipitation field in the Spanish Mediterranean zone comprises the effects of both European and African orographies, along with their synergistic effects. Further separation of these 2 factors was rejected because of the high computational effort required $\left(2^{3}\right.$ simulations for each of the 19 atmospheric patterns). Taking into account dynamic considerations, contributions of non-local orography can be generally attributed to either the Atlas range or the Alps, depending on the meteorological situation. Consequently, it is reasonable to perform a single NIPOS to analyse unambiguously the effects of such orographies on the precipitation field over the Spanish Mediterranean zone.

\section{RESULTS AND DISCUSSION}

Before looking for the effects of individual factors, we have to consider whether the precipitation fields simulated by CS are reasonably similar to the observed precipitation field, and correspondingly to its precipitation composite. For that purpose, spatial correlation coefficients and root-mean-squared errors between simulated and observed precipitation fields at model grid points for each of the 19 cases were calculated. It can be seen in Table 2 that 11 cases exhibit correlation 
Table 2. Correlation values and root-mean-square errors (RMSE; mm) between simulated and observed precipitation fields, and between simulated and composite precipitation fields, for each of the 19 atmospheric pattern groups (AP)

\begin{tabular}{|c|c|c|c|c|}
\hline \multirow{2}{*}{$\mathrm{AP}$} & \multicolumn{2}{|c|}{ Simulated vs observed } & \multicolumn{2}{|c|}{ Simulated vs composite } \\
\hline & Correlation & RMSE & Correlation & RMSE \\
\hline 1 & 0.56 & 7.15 & 0.57 & 3.99 \\
\hline 2 & 0.72 & 10.10 & 0.66 & 12.74 \\
\hline 3 & 0.70 & 12.94 & 0.76 & 15.16 \\
\hline 4 & 0.80 & 10.00 & 0.76 & 13.91 \\
\hline 5 & 0.74 & 11.72 & 0.74 & 8.93 \\
\hline 6 & 0.54 & 13.18 & 0.55 & 16.38 \\
\hline 7 & 0.41 & 7.69 & 0.55 & 6.48 \\
\hline 8 & 0.90 & 7.88 & 0.71 & 17.66 \\
\hline 9 & 0.64 & 4.28 & 0.70 & 2.55 \\
\hline 10 & 0.65 & 10.97 & 0.72 & 3.26 \\
\hline 11 & 0.34 & 6.77 & 0.86 & 3.76 \\
\hline 12 & 0.84 & 8.51 & 0.88 & 2.93 \\
\hline 13 & 0.70 & 11.13 & 0.71 & 7.67 \\
\hline 14 & 0.61 & 13.06 & 0.66 & 13.72 \\
\hline 15 & 0.42 & 16.93 & 0.41 & 9.77 \\
\hline 16 & 0.50 & 7.21 & 0.59 & 7.81 \\
\hline 17 & 0.61 & 24.85 & 0.73 & 2.84 \\
\hline 18 & 0.54 & 3.48 & 0.67 & 2.76 \\
\hline 19 & 0.36 & 4.44 & 0.43 & 2.57 \\
\hline Mean & 0.61 & 10.12 & 0.67 & 8.15 \\
\hline
\end{tabular}

values higher than 0.6. These results indicate a reasonably good model performance and make the application of the factor-separation technique meaningful. In addition, correlation coefficients with the precipitation composites are similarly good (Table 2). The displayed similarity between simulated and composite precipitation fields allows us to extrapolate the main outcomes from the single day to the represented pattern group, a necessary step to endow this study with sufficient generality.

For shortness, only 5 of the simulated days are illustrated in detail (Figs. 4 to 8). These situations comprise the main rain-bearing flow regimes that affect the Spanish Mediterranean zone, in which the 19 atmospheric circulation patterns derived in Romero et al. (1999b) can be summarized (Table 3). Each figure shows the synoptic situation and the simulated precipitation over the whole Iberian Peninsula, together with a zoom of this field over the Spanish Mediterranean zone. Also for this region, it shows the total orographic effect on the precipitation field as well as the different individual orographic effects (local, non-local and synergistic). These effects are shown only when they are significant along the domain. Observed precipitation for each of the considered situations is shown in Fig. 2.

As a summary of the results for the 19 numerically simulated atmospheric circulation patterns, Table 3 includes the role attributed to local, non-local and synergistic factors, as well as the total orographic contri- bution. Observe that the orographic actions for the main rain-bearing flows are generally consistent across the specific atmospheric patterns represented.

\subsection{Cold-front passage}

The first rain-bearing flow regime is that marked by the passage of cold fronts over the Iberian Peninsula from the Atlantic to the Mediterranean. Such situation is characterized by north-westerly winds at all levels over the Iberian Peninsula, being its western part the most affected by the north-westerly flow (Fig. 4a). Fig. 4b shows that most of the precipitation is simulated over the Atlantic side of the Iberian Peninsula and more specifically over its northwestern flank. Focusing on the Spanish Mediterranean zone, precipitation is obtained mainly over inland mountainous systems of Andalucia (Fig. 4c). These precipitation nuclei are clearly linked to the orographic forcing. Fig. $4 \mathrm{~d}$ displays that the total orographic effect consists of an enhancement of precipitation over the Andalucian highlands. This positive effect is mainly due to the local orography, as Fig. 4e confirms. In contrast, for these situations, the local orographic factor acts as a suppressive factor over the lowlands of the Spanish Mediterranean zone, which become sheltered by the prominent Iberian orography. Note also the positive local effect imposed by the well-exposed Pyrenees Mountains. Such a rainfall-enhancement mechanism explains the weak precipitation centres simulated in northern Catalonia (Fig. 4c). On the other hand, neither the non-local nor the synergistic factors are relevant for this type of flow.

\subsection{Atlantic flows}

This regime is characterized by Atlantic flows over the Iberian Peninsula (Fig. 5a). As a result of such configuration, humid southwesterly flows over the Iberian Peninsula are induced. It is worth noting how precipitation is simulated over the southwestern part of the Iberian Peninsula and the Pyrenees (Fig. 5b). Focusing on the study area, Andalucia, together with some areas over the Pyrenees and southern Catalonia, receives most of the precipitation (Fig. 5c). Precipitation over Andalucia is concentrated along its western and northern lands, more exposed to the flow than the eastern part (Fig. 1b). The total orographic effect consists basically of an enhancement of precipitation over the locations referred to above (Fig. 5d). This positive effect is mainly due to the local orography, as Fig. 5e confirms. Therefore, neither the non-local orography nor its interaction with the local orography is significant over the Mediterranean basin when affected by situations fitting this pattern. 


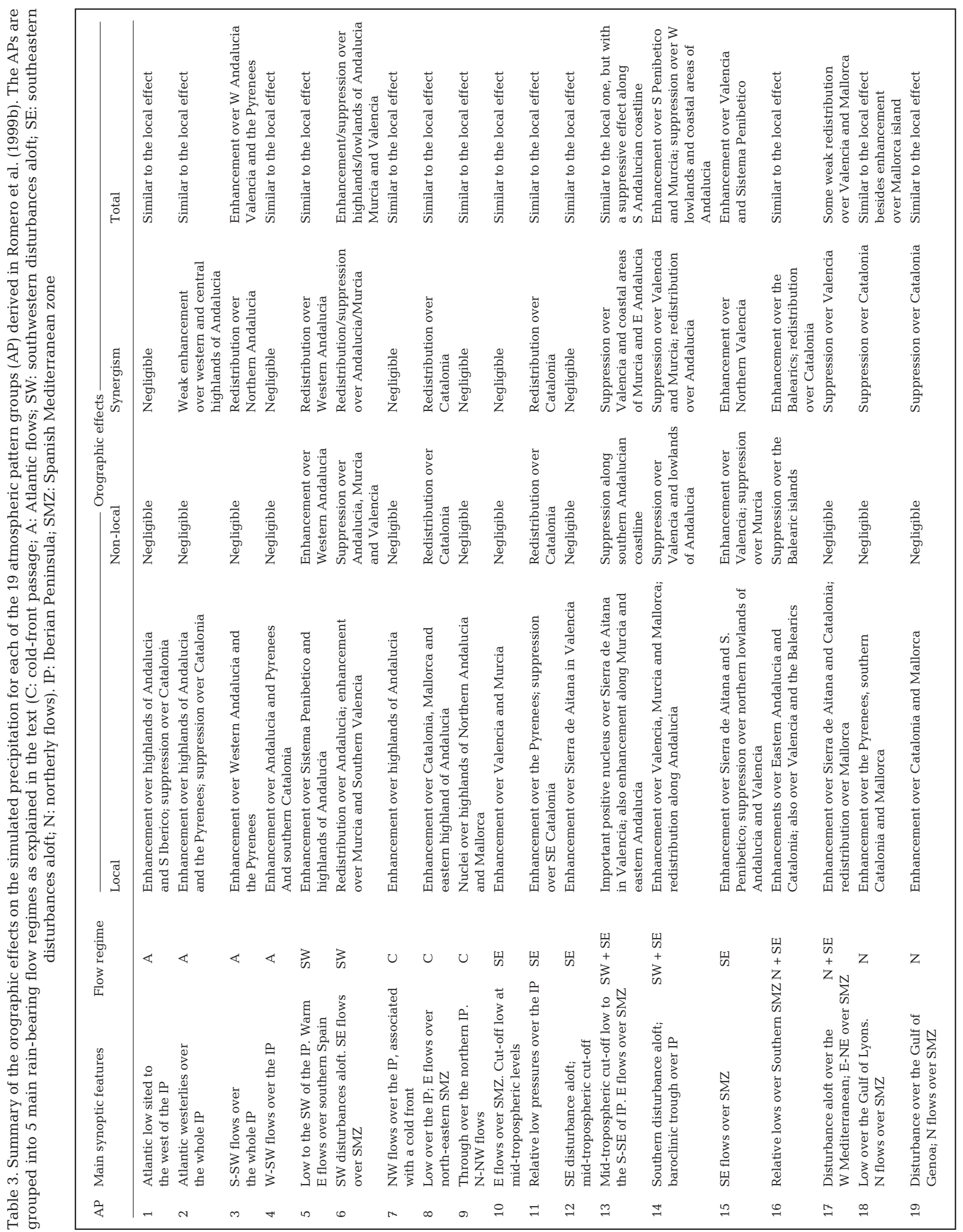



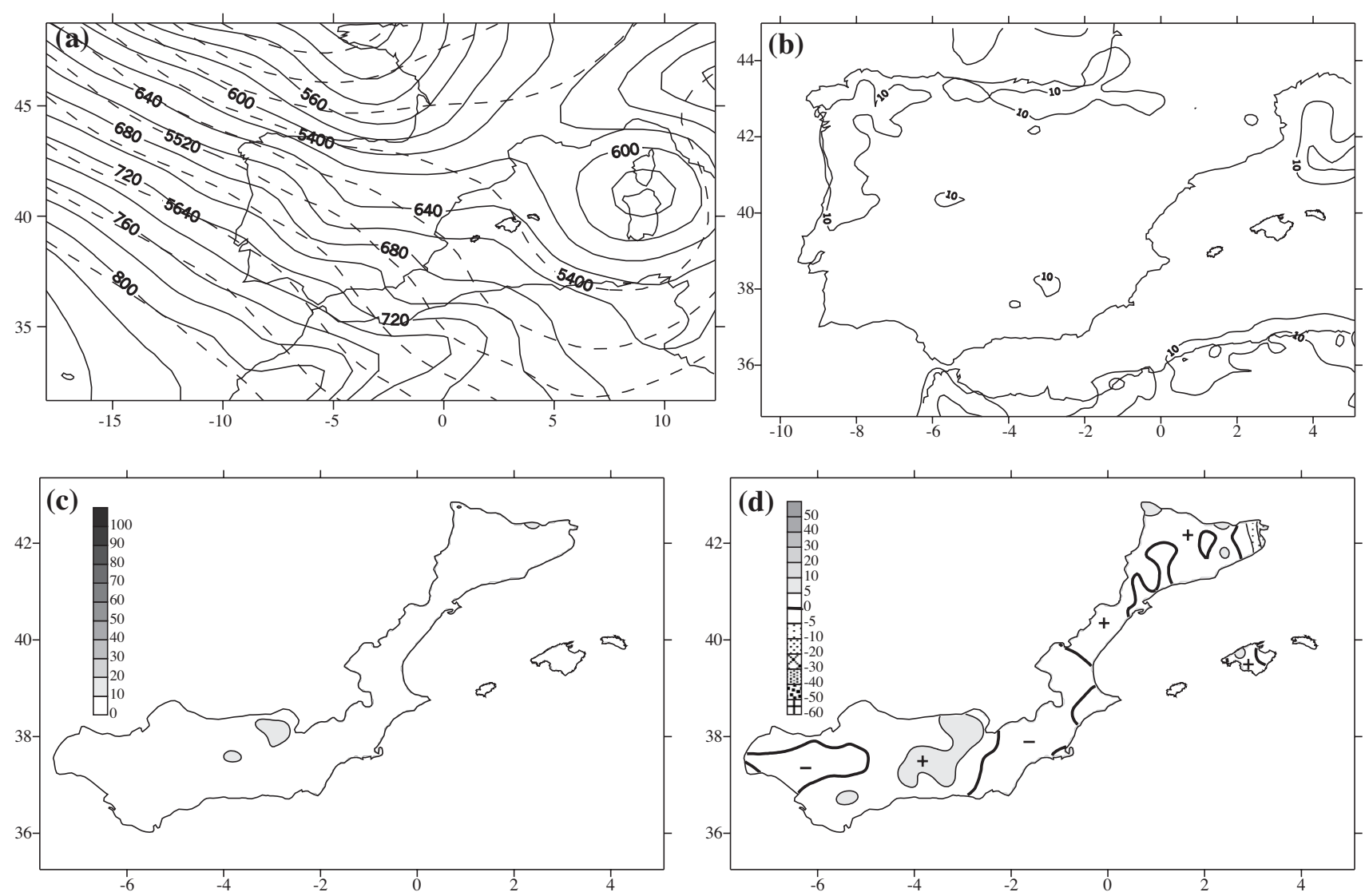

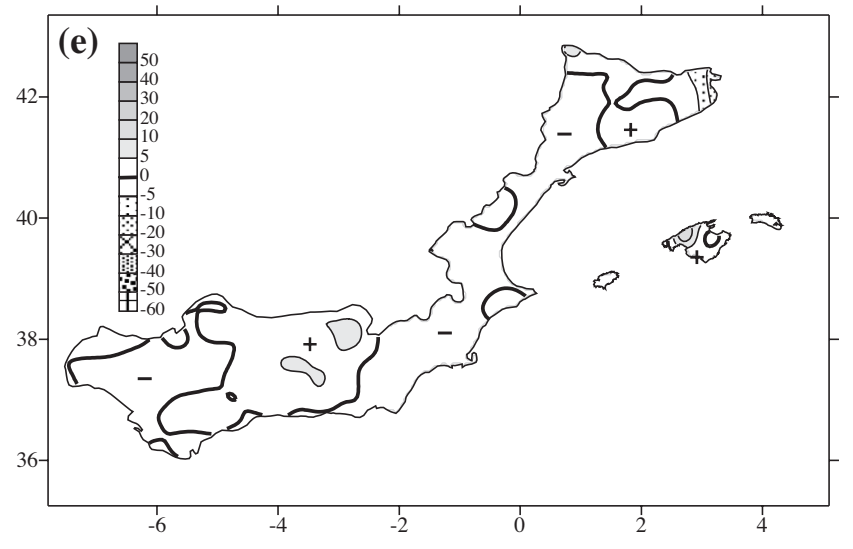

5.3. Southwestern disturbances aloft

The third rain-bearing flow regime corresponds to those situations distinguished by upper-level troughs or closed cyclonic circulations to the west of Gibraltar Strait. At the surface, the low-pressure system located over north Africa induces general easterly warm and moist flow over the Iberian Peninsula, enhanced over south-eastern Spain by a lee trough present near to the Algerian coast, linked to the Atlas mountain range (Fig. 6a). The simulated precipitation field associated with this situation exhibits widespread precipitation
Fig. 4. Cold front passage: (a) geopotential height fields at $925 \mathrm{hPa}$ (solid line) and at $500 \mathrm{hPa}$ (dashed line), contour intervals are 20 and $60 \mathrm{gpm}$ respectively; (b) total simulated precipitation (mm, contour interval is $10 \mathrm{~mm}$ ) from 06:00 h UTC to 06:00 h UTC the next day; (c) total simulated precipitation (mm) from 06:00 h UTC to 06:00 h UTC the next day for the Spanish Mediterranean zone; (d) total orographic effect, $E_{\mathrm{T}}\left(\mathrm{mm}\right.$, areas with $\left|E_{\mathrm{T}}\right|<5 \mathrm{~mm}$ are not shaded); (e) local orographic effect, $E_{\mathrm{L}}\left(\mathrm{mm}\right.$, areas with $\left|E_{\mathrm{L}}\right|<5 \mathrm{~mm}$ are not shaded)

over the southern half of the Iberian Peninsula (Fig. 6b). Focusing on the study area, apart from Murcia and south Valencia, Andalucia receives most of the precipitation (Fig. 6c). Fig. 6d shows that the total orographic effect consists of an enhancement of precipitation over the main Andalucian uplands and parts of Valencia, but suppression over Murcia, south Valencia and lowlands of Andalucia. Note that for this situation the simulated precipitation field comprises important contributions from every individual orographic factor. The local orographic factor (Fig. 6e) concentrates precipitation on the mountains and windward slopes of 

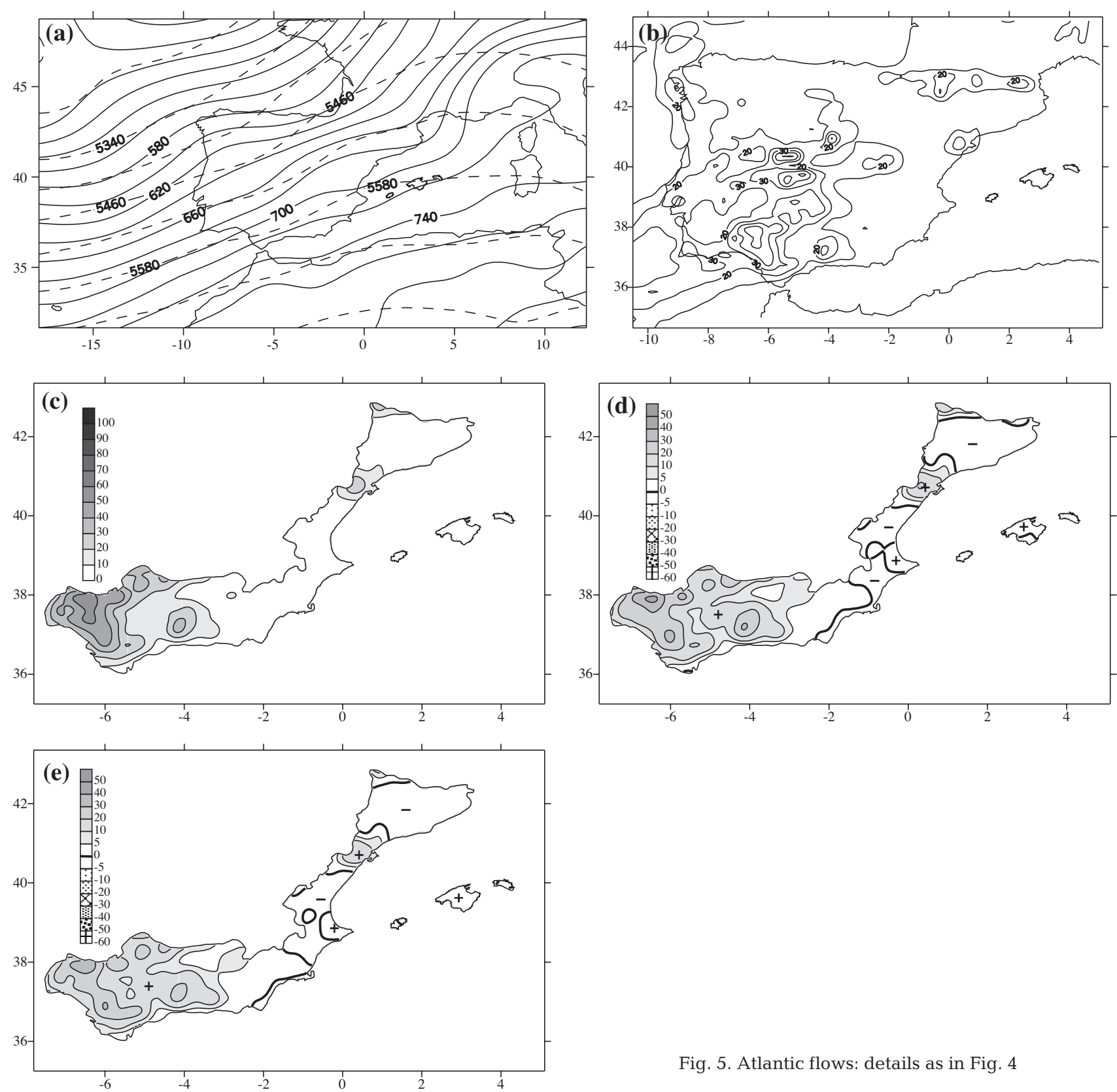

Fig. 5. Atlantic flows: details as in Fig. 4

Andalucia, as well as over Murcia and Valencia. This can be explained by the lifting provided by the orography under the impingement of the easterly low-level flow. Consequently, the negative effect observed in the western and northern lowlands of Andalucia can be explained as a sheltering effect. Some precipitation nuclei over the Pyrenees, Catalonia and Mallorca are also produced by local orographic forcing. The nonlocal orographic factor under this easterly flow regime causes a general precipitation decrease over Murcia and south Valencia (Fig. 6f). Such a decrease would result from the modification of the dynamic forcing induced by the north-Algerian-lee pressure trough.

Finally, the synergistic effect is significant over Andalucia, Murcia and Valencia (Fig. 6g). The role of the synergism for this synoptic pattern consists of a change in the direction of the impinging flow, in such a way that a redistribution of precipitation is produced over Andalucia, whereas a general negative effect is observed over Murcia and Valencia.

\subsection{Southeastern disturbances aloft}

The next synoptic situation is characterised by midtropospheric disturbances over North Africa and low- 

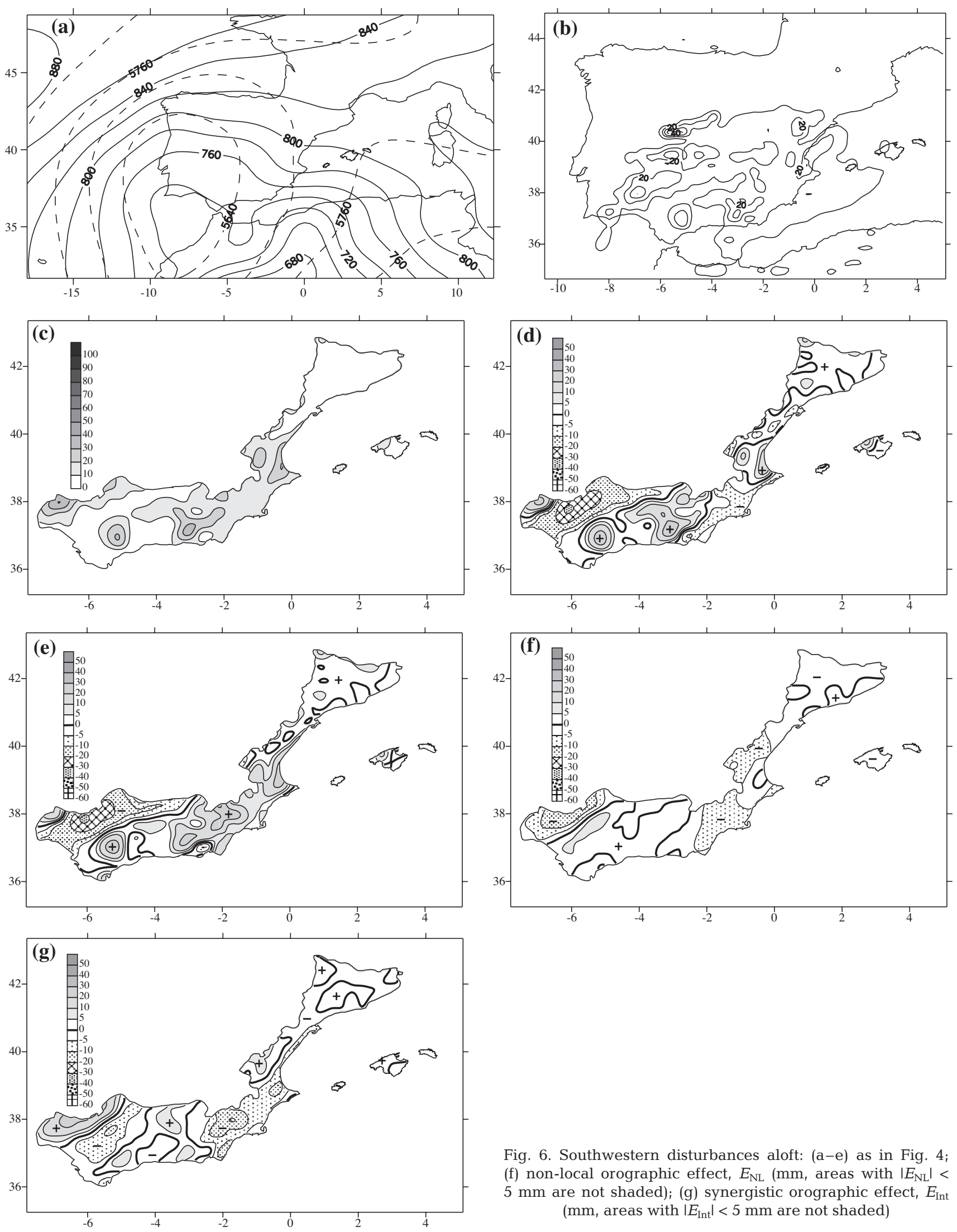

Fig. 6. Southwestern disturbances aloft: (a-e) as in Fig. 4; (f) non-local orographic effect, $E_{\mathrm{NL}}\left(\mathrm{mm}\right.$, areas with $\left|E_{\mathrm{NL}}\right|<$ $5 \mathrm{~mm}$ are not shaded); (g) synergistic orographic effect, $E_{\text {Int }}$ $\left(\mathrm{mm}\right.$, areas with $\left|E_{\text {Int }}\right|<5 \mathrm{~mm}$ are not shaded) 

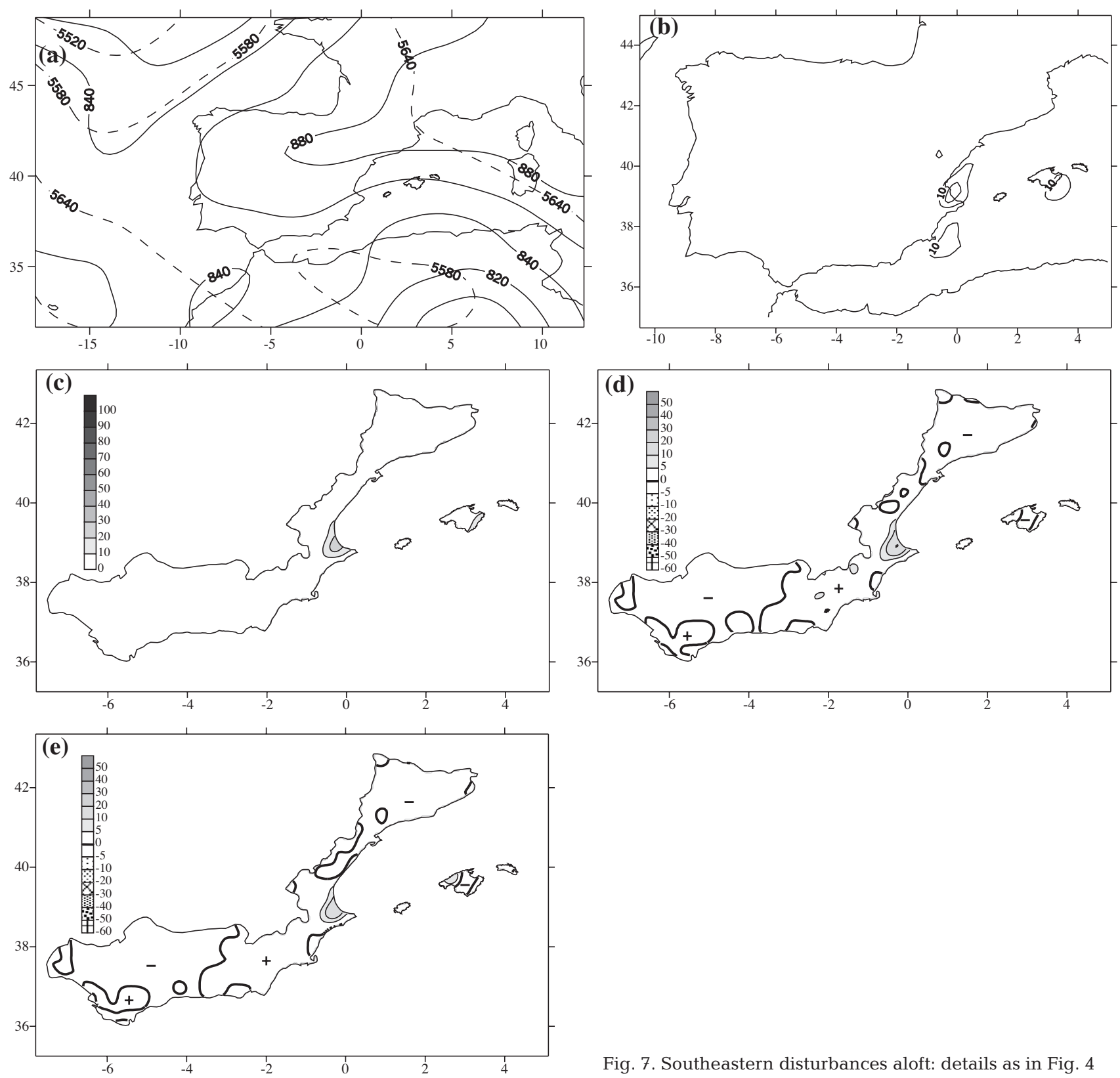

Fig. 7. Southeastern disturbances aloft: details as in Fig. 4

level easterly flows over the whole of the Spanish Mediterranean zone (Fig. 7a). The precipitation field simulated for this situation shows a precipitation nucleus over Valencia, especially over Sierra de Aitana (Fig. 7b,c). A strong positive connection between land precipitation and orography is observed in Fig. $7 \mathrm{~d}$, being almost entirely due to the local orographic forcing (note how similar the fields depicted in Fig. $7 \mathrm{~d}$ and e are). Romero et al. (1999b) showed that this type of mid-upper-tropospheric cut-off cyclone situation is statistically related to the occurrence of heavy rainfall episodes over eastern Spain. The previous results sug- gest that the interaction of the low-level easterly moist flow with the coastal orographic features is an important factor for the development of such episodes.

\subsection{Northerly flows}

The last rain-bearing flow regime illustrated corresponds to those situations distinguished by the presence of northerly or north-easterly surface flows over Spain, associated with lows sited in the northern part of the western Mediterranean basin (Fig. 8a). This con- 

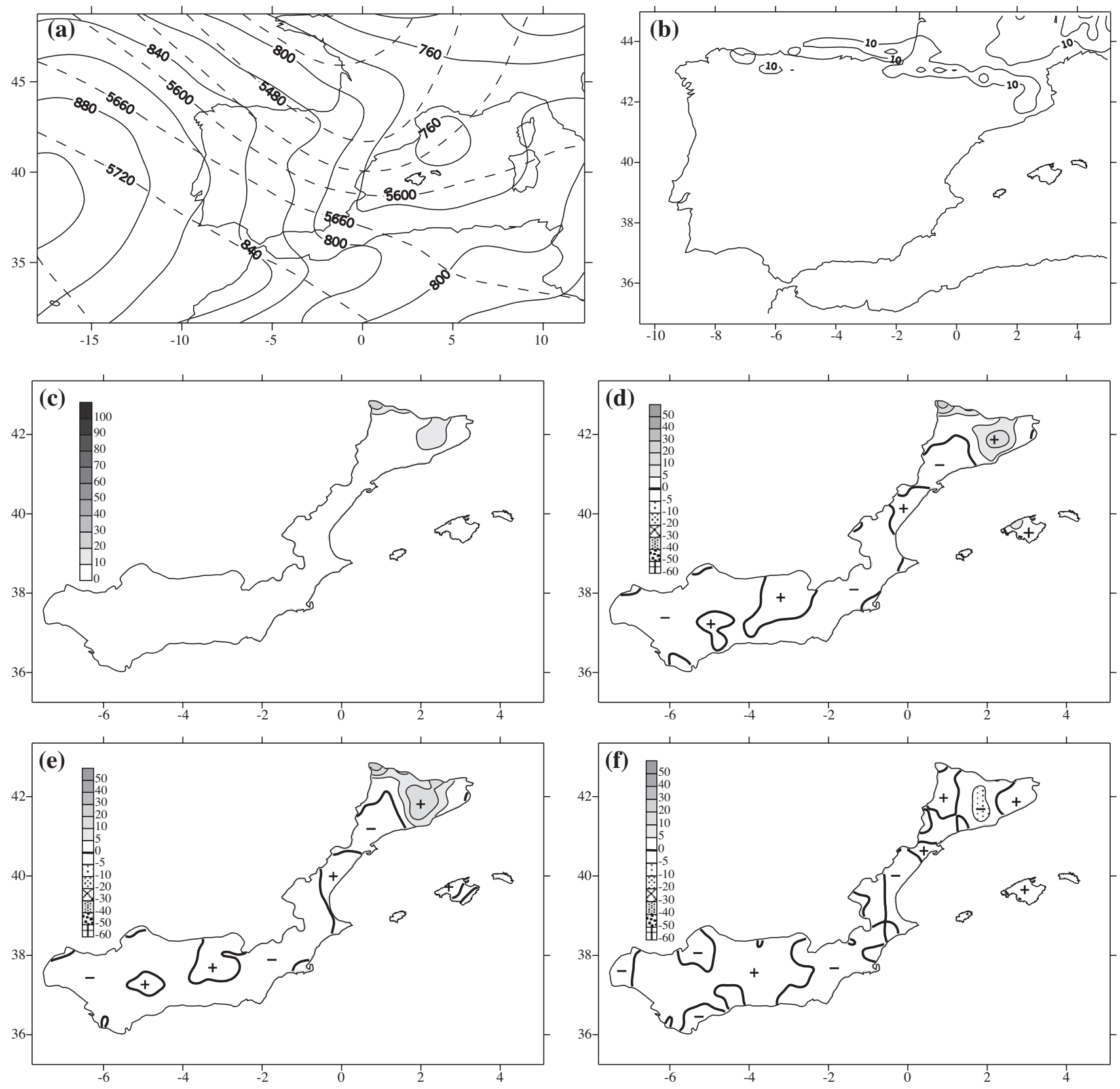

Fig. 8. Northerly flows: (a-e) as in Fig. 4 ; (f) synergistic orographic effect, $E_{\text {Int }}\left(\mathrm{mm}\right.$, areas with $\left|E_{\text {Int }}\right|<5$ mm are not shaded)

figuration leads to a simulated precipitation field marked by precipitation over northeastern Spain and particularly over the Pyrenees (Fig. 8b,c). The precipitation field for this situation is controlled by local orographic enhancements over these areas (Fig. 8d,e). Such enhancements are clearly due to the impingement of the northerly flow against the Pyrenees relief and other Catalonian highlands. In contrast, non-local orographic effects are negligible for this situation. However, a negative synergistic effect is observed over
Catalonia (Fig. 8f). This precipitation suppression over Catalonia could be related to the action exerted by the French Central Massif and the Alps on the nearsurface impinging airflow.

\section{CONCLUSIONS}

A study of the orographic influence on the spatial distribution of precipitation in Mediterranean Spain 
was derived through numerical simulations. The roles of the Iberian orography, as a local factor, the external orography, as a remote agent, and their interaction were isolated following the factor-separation technique of Stein \& Alpert (1993). The simulated meteorological situations are representative of the 19 characteristic atmospheric patterns that produce significant rainfall in the Spanish Mediterranean zone (Romero et al. 1999b).

The results illustrate quantitatively that orography is a key factor for the spatial distribution of precipitation over the Spanish Mediterranean zone. It is explicitly shown that the complex orography favours precipitation on highlands exposed to the airflow, and therefore a reduction of precipitation on surrounding sheltered lowlands. Clear examples of areas prone to precipitation enhancement shown in the text are: Sierra de Aracena, Sierra de Ronda and Sistema Penibético in Andalucia; Sierra de Aitana and Sistema Ibérico in Valencia; Sierra de Tramuntana in Mallorca; and the Pyrenees in Catalonia. For most of the precipitationproducing atmospheric scenarios analysed in the study, the orographically enhanced precipitation over these ranges represented almost all their total simulated precipitation.

Regarding individual contributions of the local and non-local orographies as well as their interaction, a clear dependence on the meteorological situation appears. In fact, when a low-pressure system lies to the west or northwest of the Iberian Peninsula, producing humid Atlantic flows, as well as under the passage of cold fronts, local orography generally emerges as the unique significant factor. On the other hand, when easterly flows at low levels appear over the Spanish Mediterranean zone, the effects of non-local orography and synergism can become relevant, with the remarkable role of the Atlas range. Even though the local factor also affects crucially these situations, by redistributing precipitation through the aforementioned mechanisms, the remote action of the Atlas range results in a precipitation decrease over the southern Spanish Mediterranean zone. This effect is especially important when the upper-level flow is from the south-southwest (southwestern disturbances aloft), and in response, a surface trough develops in the lee of the Atlas range over the Algerian coast. The interaction between local and non-local factors is also significant in these cases. Effectively, modification of the low-level flux by the action of the Atlas range and the resulting modified impingement on the Iberian orography relocate low-level divergence/convergence zones and thus induce a redistribution of precipitation. These findings extend previous results dealing with the role of orography in the onset of heavy precipitation in eastern Spain under such synoptic scenarios (e.g.
Romero et al. 1997, Ramis et al. 1998, Homar et al. 1999).

Finally, when northerly flows occur over the Spanish Mediterranean zone, usually with a low over the Gulf of Lyons or the Gulf of Genoa, precipitation is only observed over the northeastern part of the region. The local orography is again the leading factor, the nonlocal effect is negligible and the interaction causes general rainfall suppression over Catalonia. Unlike the easterly flow regimes, this interaction with the local orography is basically exerted by the Central Massif and the Alps.

All the above results suggest that a successful application of regional models, from numerical weather prediction to dynamic downscaling of climate scenarios, might require high resolution and large domain dimensions in order to capture adequately both local and non-local orographic features.

Acknowledgements. Precipitation and ECMWF data were provided by the Instituto Nacional de Meteorología (INM) of Spain. We wish to thank the reviewers for their constructive comments, which helped to improve the content and presentation of this paper. This work has been partially sponsored by CICYT CLI98-1177-E and CLI99-0269 grants.

\section{LITERATURE CITED}

Buzzi A, Tibaldi S (1978) Cyclogenesis in the lee of the Alps: a cause study. Q J R Meteorol Soc 104:271-287

Davies HC (1976) A lateral boundary formulation for multilevel prediction models. Q J R Meteorol Soc 102:405-418

Font I (1983) Climatology of Spain and Portugal. Instituto Nacional de Meteorología, Madrid

Homar V, Ramis C, Romero R, Alonso S, Garcia-Moya JA, Alarcon M (1999) A case of convection development over the western Mediterranean Sea: a study through numerical simulations. Meteorol Atmos Phys 71:169-188

Källén E (1996) HIRLAM documentation manual. SMHI, Norrkoping

Louis JF (1979) A parametric model of vertical eddy fluxes in the atmosphere. Boundary Layer Meteorol 17:187-202

Machenhauer B (1977) On the dynamics of gravity oscillations in a shallow water model with applications to normal mode initialization. Beitr Atmos Phys 50:253-271

Ramis C, Romero R, Homar V, Alonso S, Alarcón M (1998) Diagnosis and numerical simulation of a torrential precipitation event in Catalonia (Spain). Meteorol Atmos Phys 69:1-21

Reiter ER (1975) Handbook for forecaster in the Mediterranean weather phenomena in the Mediterranean basin. Monterrey Cal Tech Paper No. 5-75. Environmental Prediction Research Facility, Naval Postgraduate School, Monterrey, CA

Romero R, Ramis C, Alonso S (1997) Numerical simulation of an extreme rainfall event in Catalonia: role of the orography and evaporation from the sea. Q J R Meteorol Soc 123: $537-559$ 
Romero R, Ramis C, Guijarro JA (1999a) Daily rainfall patterns in the Spanish Mediterranean area: an objective classification. Int J Climatol 19:95-112

Romero R, Sumner G, Ramis C, Genoves A (1999b) A classification of the atmospheric circulation patterns producing significant daily rainfall in the Spanish Mediterranean area. Int J Climatol 19:765-785

Savijärvi H (1990) Fast radiation parameterization schemes for mesoscale and short range forecast models. J Appl

Editorial responsibility: Hans von Storch, Geesthacht, Germany
Meteorol 20:437-447

Stein U, Alpert P (1993) Factor separation in numerical simulations. J Atmos Sci 50:2107-2115

Sundqvist H, Berge E, Kristansson J (1989) Condensation and cloud parameterization studies with a mesoscale numerical weather prediction model. Mon Weather Rev 117: 1641-1657

Temperton C (1988) Implicit normal mode initialization. Mon Weather Rev 116:1013-1031

Submitted: May 18, 2002; Accepted: August 5, 2002 Proofs received from author(s): January 28, 2003 